\section{Reply to L.E. Daly et al}

We thank Daly et $\mathrm{al}^{1}$ for providing valuable comments regarding our recent paper on the prognostic role of muscle loss during anticancer treatment in patients with metastatic colorectal cancer. ${ }^{2}$ We have found that muscle mass decreased significantly during chemotherapy and a decrease in muscle mass was independently associated with poor survival in patients with metastatic colorectal cancer. Daly et $\mathrm{al}^{1}$ correctly note that we observed no associations between a low skeletal muscle index at baseline and reduced survival, in contrast to some but not all previous studies. In our article, we provide some explanations for this discrepancy, for example, the heterogeneity regarding treatment regimens and follow-up time. ${ }^{2}$ Daly et al add a possible explanation as there may be a possible difference in body composition reference values between a North American (Canadian) and European population. Daly et al suggest that extrapolating cutoff points from a Canadian population to a cohort of Dutch patients may have been a suboptimal approach to identify the true prevalence of low SMI and the relationship between low SMI and survival within this cohort. We acknowledge the importance of differences in body composition between countries. For example, the Dutch population, on average, is taller and the prevalence of overweight and obesity is lower compared with the Canadian population. ${ }^{3,4}$ Although a large percentage of the Canadian population consists of (European) immigrants, ${ }^{5}$ we agree that it would be better to compare our study data with normative values derived from a European, or even a Dutch, population. Although we did find a new publication with cutoff values for an Asian population, ${ }^{6}$ normative data for a European population are not available yet.

There are several options to consider to overcome the question of ethnic variation in body composition in the near future. Data on body composition measured with computed tomography scans from recent European studies ${ }^{7-10}$ could be pooled to build a database with reference values for the European population. Another approach is to derive normative values from a healthy population, which is what our group is working on at the moment. It would then be interesting to repeat the statistical analyses of our study and to investigate whether our population truly displayed a low skeletal muscle index compared with European reference values. Only then we will be able to understand why skeletal muscle index was not associated with survival in our cohort and whether this may have been caused by choosing the wrong reference group.

In the meantime, while we await reference values for different countries and/or ethnic groups, we recommend that future studies on body composition display patient characteristics with regard to ethnicity, especially when cutoff values or reference values are being used. This does not apply to Europe alone, but also to other regions across the world.

\section{Susanne Blauwhoff-Buskermolen \\ VU University Medical Center, Amsterdam, the Netherlands}

\section{Marian A.E. de van der Schueren}

VU University Medical Center, Amsterdam, and HAN University of Applied Sciences, Nijmegen, the Netherlands

\section{Jacqueline A.E. Langius}

VU University Medical Center, Amsterdam, and The Hague University of Applied Sciences, The Hague, the Netherlands

\section{Henk M.W. Verheul}

VU University Medical Center, Amsterdam, the Netherlands

\section{AUTHORS' DISCLOSURES OF POTENTIAL CONFLICTS OF INTEREST}

Disclosures provided by the authors are available with this article at www.jco.org.

\section{REFERENCES}

1. Daly LE, Ryan AM, Power DG: Re: Loss of muscle mass during chemotherapy is predictive for poor survival of patients with metastatic colorectal cancer. $\mathrm{J}$ Clin Oncol 34:3816-3817, 2016

2. Blauwhoff-Buskermolen $S$, Versteeg KS, de van der Schueren MA, et al: Loss of muscle mass during chemotherapy is predictive for poor survival of patients with metastatic colorectal cancer. J Clin Oncol 34:1339-1344, 2016

3. National Institute for Health and the Environment: Prevalence of overweight and obesity in the Netherlands in 2015. https://www.volksgezondheidenzorg.info/ onderwerp/english/introduction

4. Shields M, Connor Gorber S, Janssen I, et al: Bias in self-reported estimates of obesity in Canadian health surveys: An update on correction equations for adults. Health Rep 22:35-45, 2011

5. Citizenship and Immigration Canada: Statistics. http://www.cic.gc.ca/english/ resources/statistics/

6. Hamaguchi Y, Kaido T, Okumura S, et al: Proposal for new diagnostic criteria for low skeletal muscle mass based on computed tomography imaging in Asian adults. Nutrition 10.1016/j.nut.2016.04.003 [epub ahead of print on May 4, 2016]

7. Stene GB, Helbostad JL, Amundsen T, et al: Changes in skeletal muscle mass during palliative chemotherapy in patients with advanced lung cancer. Acta Oncol 54:340-348, 2015

8. Weijs PJM, Looijaard WGPM, Dekker IM, et al: Low skeletal muscle area is a risk factor for mortality in mechanically ventilated critically ill patients. Crit Care 18:R12, 2014

9. van Vledder MG, Levolger S, Ayez N, et al: Body composition and outcome in patients undergoing resection of colorectal liver metastases. $\mathrm{Br} J$ Surg 99: 550-557, 2012

10. Thoresen L, Frykholm G, Lydersen S, et al: The association of nutritional assessment criteria with health-related quality of life in patients with advanced colorectal carcinoma. Eur J Cancer Care (Engl) 21:505-516, 2012

DOI: 10.1200/JCO.2016.68.9364; published online ahead of print at www.jco.org on August 1, 2016. 
AUTHORS' DISCLOSURES OF POTENTIAL CONFLICTS OF INTEREST

Reply to L.E. Daly et al

The following represents disclosure information provided by authors of this manuscript. All relationships are considered compensated. Relationships are self-held unless noted. I = Immediate Family Member, Inst = My Institution. Relationships may not relate to the subject matter of this manuscript. For more information about ASCO's conflict of interest policy, please refer to www.asco.org/rwc or jco.ascopubs.org/site/ifc.

Susanne Blauwhoff-Buskermolen

No relationship to disclose

Marian A.E. de van der Schueren

Speakers' Bureau: Nutricia
Jacqueline A.E. Langius

Travel, Accommodations, Expenses: Nutricia

Henk M.W. Verheul

Consulting or Advisory Role: Boehringer Ingelheim (Inst)

Research Funding: Amgen (Inst) 